\title{
Narcissus (Daffodil) Phototropism, Applications to Alzheimer's Drug Development
}

\author{
Peter R. Greene, Ph.D. ${ }^{1}$, Virginia A. Greene, M.S., AIAA ${ }^{2}$, James J. Vigneau ${ }^{3}$ \\ ${ }^{1}$ BGKT Consulting Ltd., Bioengineering, Huntington, New York, 11743 \\ ${ }^{2}$ VGA Architects PC, Chicago, Illinois, 60604 \\ ${ }^{3}$ Biology, State Univ. of New York, USA
}

*Corresponding Author: Peter R. Greene, BGKT Consulting Ltd., Bioengineering, Huntington, New York, USA.

\begin{abstract}
Pharmaceutical daffodil alkaloid extracts are currently being developed to control Alzheimer's disease. In general, practical factors controlling plant growth-rate are of interest, both in terms of cellular and commercial aspects. In terms of methods, leaf and flower stem longitudinal growth rates are measured for daffodil plants protected by an overhead canopy and compared with those for normal unprotected control plants. Stem lengths and variable geometry diameters are also reported. Results include measurements of leaves and flower stems of normal daffodil plants ( $N$. pseudo-narcissus) growing 0.3 to 0.4 meters in length over a 6 week interval during the Spring. In response to reduced snow, wind and rain forces, and less ambient light, daffodil plants protected by an overhead canopy demonstrate enhanced growth rates, doubling in length to 0.6 to 0.8 meters, over the same time interval, $p<0.0001$. The conclusion is that mechanisms for this unusual rate-doubling phenomenon include mechanosensing and/or phototropism, both of which can be controlled with a protective canopy. Practical applications include the development of Alzheimer's control drugs from chemical extracts derived from the narcissus plant.
\end{abstract}

Keywords: daffodil plant; N. pseudo-narcissus; enhanced growth; Alzheimer control drugs; protective canopy; phototropism; mechanosensing

\section{SignificAnCE STATEMENT}

Narcissus (daffodil plant) growth rates are doubled or tripled during development (2X to $3 \mathbf{X}$ )due to overhead shading, producing flower stems $\sim 3 \mathrm{ft}$. tall, compared with $\sim 1 \mathrm{ft}$. tall under normal open field circumstances $(\mathrm{p}<0.0001)$.

Practical applications include the accelerated or enhanced production of alkaloid extracts, used for the production of modern Alzheimer drugs.

\section{INTRODUCTION}

Left to their own devices under normal unrestricted conditions, the daffodil plant (N. pseudonarcissus)impeded (or encouraged) by the environment, grows 12 to 16 inches in length ( 0.3 to 0.4 meters) over a 6week interval, as shown in Fig. 1a. Both leaves and flower stems attain approximately the same height.

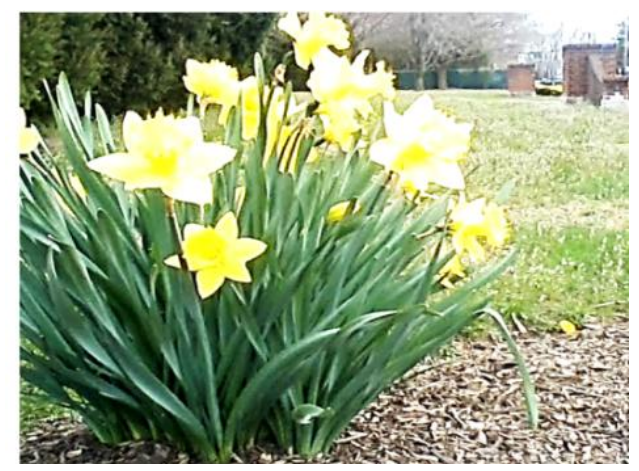

Fig1a. Normal unimpeded growth of daffodils, 3rd week of April 2018, 12 to 16 inches in length (0.3 to 0.4 meter) flower stalk and leaves, (view facing south, most flowers facing west). 
Found locally on the North Shore of Long Island, latitude $\sim 41^{0} \mathrm{~N}$ (as elsewhere)these plants typically bloom during the 1st, 2nd, or 3rd week of April, favoring the later dates, according to the severity of the winter months. Hanks (2003) reports daffodil sensitivity to temperature effects integrated over the winter months.

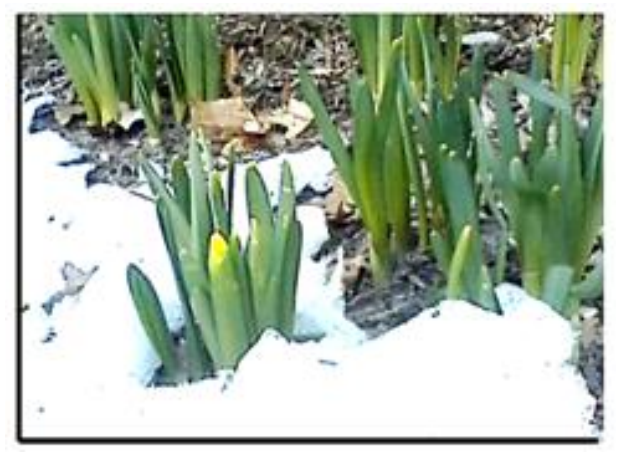

Fig1b. Undeterred by snow and harsh winter months, daffodil bulbs sprout during the 1st week of March 2018. Six (6) weeks later, the flower stems bloom, Fig. la above, (view facing east).

This year, the leaf and flower stalks made their first appearance ${ }^{\wedge}$ during the 1 st week of March, Fig. $1 \mathrm{~b}^{\wedge}$, with the daffodil flowers not blooming until the 2nd week of April, 6 weeks later. These plants continue growing somewhat throughout April, but the daffodil flowers only last 2 to 3 weeks, (Hanks (2003)). As reported here, daffodil plants that are partially or completely protected with an overhead canopy exhibit enhanced growth rates, double the rate of the nearby normal control plants.

Commercially speaking, in terms of pharmaceutical applications, chemicals extracted from such narcissus plants (i.e. alkaloid derivatives) are recently finding application to the difficult problem of Alzheimer's disease (Hanks (2003)). The purpose of this report is to quantify this unusual lengthdoubling phenomenon, in terms of rates of growth, stem and leaf geometries, and the extent of overhead canopy cover. Hanks (2003) reports that daffodils are phototropic, similar to sunflowers, redirecting the flowers towards the sun, a finding reconfirmed here. Environmental factors controlling plant growth-rate are of interest, both in terms of the cellular and commercial aspects.

\section{Materials ANd Methods}

Experimental observations and measurements are made during the period March 1st to April 30th. The open-field unprotected daffodils are observed to grow in groups of 10 to 15 plants, as shown in Figs. 1a-1c. Four (4) rapidly growing extra-long daffodils are located, growing under protective canopies provided by overhead shrubs. These "doubly-enhanced" plants, Figs. 2a, 2b, are firmly anchored in the ground, not sprouting from an elevated position in the Cypress shrub, as conceivably might be the case. The plant "wends" its way through the shrub, compensating with extra flower stem and leaf growth, twice normal.

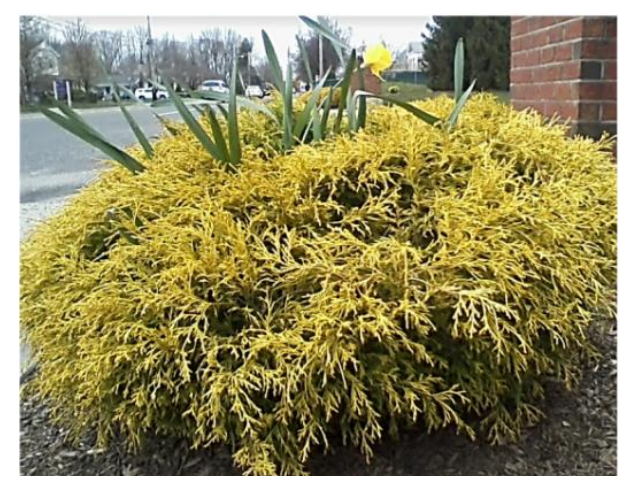

Fig2a. Same species of daffodil as shown in Fig. 1, growing a few yards away, buried beneath an 18-inch (0.5 meter) Cypress shrub. The plant "wends" its way through the shrub, compensating with extra flower stem and leaf growth, doubling in length to 30-inches (0.76 meters) during April 2018, (view facing north, flower facing east). The pointed leaves easily penetrate the shrub, but several flower stems are lost because the flower is larger in diameter. 


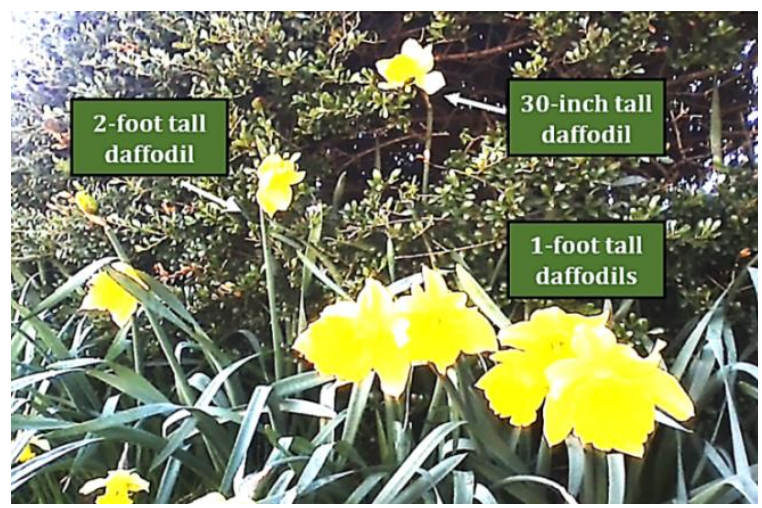

Fig2b. Length doubling of the daffodil flower stem is also observed with partial shrouding at the edge of a taller shrub. The enhanced 30-inch (0.76 meter) flower stem has already buckled (crimped) under the weight of the flower. Stem diameters are the same for both normal and enhanced daffodil plants, (view facing west, most flowers facing east).

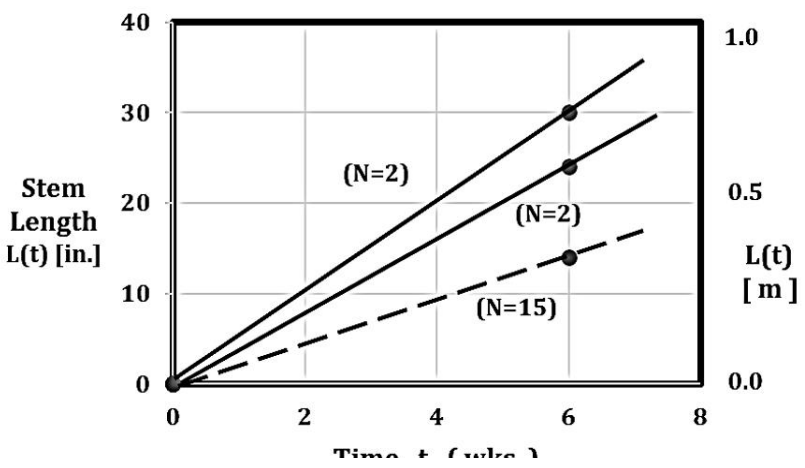

Fig2c. daffodil flower stem growth rates for $N=15$ open field control plants growing to 0.4 meters in 6 weeks, $N=2$ plants that are partially protected with an overhead canopy growing to 0.6 meters, and $N=2$ plants with a complete canopy growing to 0.8 meters in 6 weeks.

The Student's t-test $\wedge$ is used to compare the normal control plants $(\mathrm{N}=15,16)$ with the rapidly growing protected daffodils $(\mathrm{N}=4,5)$, showing that the results are highly significant, $\mathrm{p}<0.0001$, $\mathrm{df}=$ $17, \mathrm{t}=10.46$, using Graph Pad. These results are confirmed with a 5th daffodil plant (not shown) whose leaves grow to double the normal length, but whose flower stems do not survive, unable to penetrate through the overhead canopy.

Leaf and stem length $\mathrm{L}$ [meters] and stem diameters at base (D2, D3, [mm]) and flower height (D0, D1, [mm]) are measured with an English/metric ruler, accuracy of measurement is $+/-2.5 \mathrm{~cm}$ for lengths, $+/-1.0 \mathrm{~mm}$ for diameters, Table 1 . Wall thickness of the hollow double-ogive flower stems is $\sim 0.5 \mathrm{~mm}$. Photographs were taken with a flip-style camera phone, resolution 1.3 mega-pixels, transferred to Micro Soft Power Pt.

Table1. Daffodil Stem Geometry

\begin{tabular}{|c|c|c|c|c|}
\hline $\begin{array}{l}\text { Enhanced Growth } \\
\text { Plants }(\mathrm{N}=4,5)\end{array}$ & $\begin{array}{l}\text { Flower } \\
\text { StemLength L }\end{array}$ & $\begin{array}{l}\text { Stem Diam. D0,D1 } \\
\text { @ flower height }\end{array}$ & $\begin{array}{l}\text { Stem Diam. D2,D3 } \\
\text { @ base height }\end{array}$ & $\begin{array}{l}\text { Flower Stem } \\
\text { Growth Rate }\end{array}$ \\
\hline $\begin{array}{l}18 " \text { Shrub, }(0.46 \mathrm{~m}, \\
100 \% \text { canopy, } \mathrm{N}=1)\end{array}$ & $\begin{array}{l}\text { 30-inch } \\
\text { ( } 0.76 \text { meters) }\end{array}$ & $\begin{array}{l}4 \mathrm{~mm} \\
7 \mathrm{~mm}\end{array}$ & $\begin{array}{l}8 \mathrm{~mm}, \\
11 \mathrm{~mm}\end{array}$ & $10 \mathrm{~cm} /$ week \\
\hline $\begin{array}{l}\text { 36" Shrub(0.91 m, 50\% } \\
\text { canopy, N=1) }\end{array}$ & $\begin{array}{l}30-\text { inch } \\
(0.76 \text { meters })\end{array}$ & $\begin{array}{l}5 \mathrm{~mm} \\
7 \mathrm{~mm}\end{array}$ & 66 & 66 \\
\hline ( 2 plants $)$ & $\begin{array}{l}24-\text { inch } \\
(0.61 \text { meters })\end{array}$ & $\begin{array}{l}6 \mathrm{~mm} \\
8 \mathrm{~mm}\end{array}$ & $\begin{array}{l}9 \mathrm{~mm} \\
12 \mathrm{~mm}\end{array}$ & $8 \mathrm{~cm} /$ week \\
\hline
\end{tabular}

\begin{tabular}{|l|l|l|l|l|}
\hline Normal Controls & $\begin{array}{l}16-\text { inch } \\
\text { (N=15,16) }\end{array}$ & $5 \mathrm{~mm}$ & $9 \mathrm{~mm}$ & $5 \mathrm{~cm} /$ week \\
\hline $\mathbf{6} \mathbf{6}$ & 12-inch & $5 \mathrm{~mm}$ & $13 \mathrm{~mm}$ & \\
& $(0.30$ meters $)$ & $7 \mathrm{~mm}$ & $9 \mathrm{~mm}$ & $5 \mathrm{~cm} /$ week \\
\hline
\end{tabular}

Accuracy $=+/-2.5 \mathrm{~cm}$ for stem length, +/- $1.0 \mathrm{~mm}$ for stem diameters 
Control group. Outdoors, the environmental conditions for the normal daffodil plants are virtually identical with those for the enhanced growth plants, located within a few feet. These controlled conditions include temperature, humidity, rain, soil, hydration, sunlight, wind, snow, light-cycle, etc. The only difference between the controls and the enhanced plants is the presence or absence of the overhead protective canopy, allowing a direct application of the Student's t-test, evaluating the significance of the difference of the two groups (i.e. normal versus enhanced), as presented in the Results section.

\section{Results}

Enhanced growth rates. Developing plants adapt to the demands and restrictions of the environment, in order to absorb sufficient sunlight. Buried beneath an 18-inch (0.5 meter) Cypress shrubbery, both the daffodil flower stems and leaves are observed to accelerate their growth during April, doubling in length to 0.6 to 0.8 meters, as shown in Figs. $2 \mathrm{a} \& 2 \mathrm{~b}, \mathrm{~N}=4$ plants. Evidently, the quality and quantity of available solar photons beneath the canopy of the shrub are not sufficient for the plant.

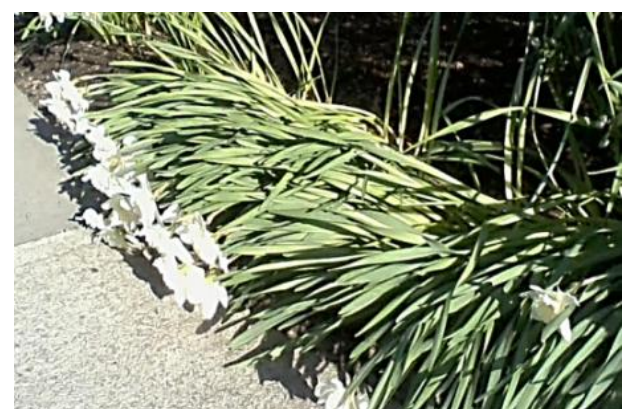

Fig1c. The weight of a moderate rain shower is sufficient to collapse the entire daffodil plant to the ground. 24 hours later, as shown, the plants have partially recovered. 2 to 3 days are required for full upright recovery, (view facing east, most flowers facing north).

Snow \& rain forces. As shown in Fig. $1 \mathrm{c}^{\wedge}$, snow and frozen ground restraints during March do not deter the newly developing plants, as long as the leaves and stems are fairly short compared with their diameter, and thus resistant to bending or breaking. No stem or leaf buckling is observed at this time. However, during April, when the stems and leaves are longer, close to adult length, a moderate to heavy rainfall with wind weights down the leaves and stems to the point where they buckle, literally collapsing the entire plant to ground level, Fig. 1c, for several days ensuing. Thus, the protective umbrella of the shrub canopy, a Gold Mop Cypress, Fig. 2a, (Chamaecyparis pisifera) allows the developing daffodil plant to avoid this buckling problem due to inclement weather (rain and wind forces), thereby growing to double the normal height.

Growth rates. Unimpeded (i.e. unprotected), the normal open-field daffodil stems and leaves, Fig. 1a, are observed to grow $0.3 \mathrm{~m}$ in 6 wks. during March-April, an average growth rate of $5 \mathrm{~cm} / \mathrm{wk}$. By contrast, the restricted (i.e. protected) daffodil stems and leaves beneath the canopy of the shrub, grow at an accelerated rate of $10 \mathrm{~cm} / \mathrm{wk}$, double the normal rate, as shown in Figs. 2a, 2b, 2c,and Table 1. Statistical data used with the Student's t-test are $\mathrm{N}_{1}=14$ control plants, $\mathrm{N}_{2}=4$ enhanced plants, significance $\mathrm{p}<0.0001$.

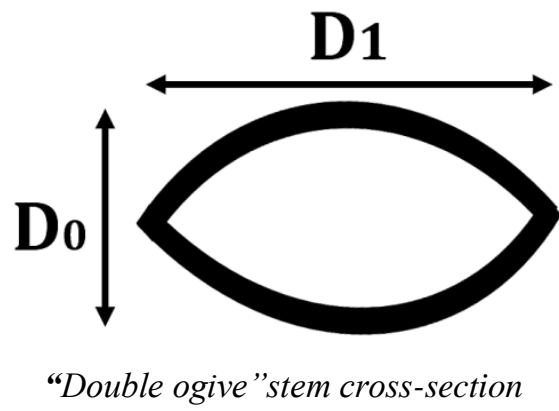

Double-ogive stems. Table 1 presents geometric data for extra-long flower stem geometry for $\mathrm{N}=4$ "protected" daffodils (1 plant @ 100\% canopy, 3 plants@50\% canopy) compared with the shorter "unprotected" plants (open field, with no overhead canopy). Note that the short 12-16 inch (0.3 to 0.4 m) stems are the same thickness, but the "protected" daffodils are $2 X$ times taller. 
The flower stems are lenticular or "double-ogive" in cross section, so 2 diameters are required at base (D0, D1) tapering to two smaller diameters at flower height (D2, D3) in order to specify stem dimensions, as shown in Table 1. A complete analysis of stem bending deflections and cross-sectional moment of inertia is beyond the scope of this report. However, in traditional engineering terms, the double-ogive stem geometry is midway between a rectangular "box-beam" and a circular tubeinterms of mechanical properties. The tapering geometry allows for flexibility in wind, consistent with the general growth strategy "it is better to bend, than to break".

Other species. Comparing with another species, the wild dandelion (Hypochaeris) grows at $30 \mathrm{~cm} / \mathrm{wk}$ [4], 3 times faster than the "enhanced" daffodil, during June. Normal flower stem diameter for daffodils is 7 to $13 \mathrm{~mm}$ at base (ground level), and 5 to $7 \mathrm{~mm}$ at flower height. The taller "canopy enhanced" daffodils ( $\mathrm{N}=4$ plants) have leaves and flower stems that are comparable in diameter, Table 1, and thus more prone to buckling, because of the extended length, as shown in Fig. 2b (arrow points to crimped stem at the location of buckling).

\section{DISCUSSION}

Possible mechanisms. Ambient sunlight, snow and rain are partially blocked by the shrubbery, so the plant evidently compensates by growing taller, doubling stem and leaf length. Possible mechanisms for this unusual rate-doubling phenomenon include mechanical and/or optical effects.

In the mechanical domain, mechanosensing (Greene et al. $(2015,2017)$ ) is a phenomenon whereby the stalks react, growing stronger (or weaker) in response to stress, strain, and buckling loads imposed by the environment, typically wind and rain driven forces. In this instance for the daffodil, mechanosensing is possibly a matter of arresting or slowing growth, because buckling causes "crimping" of the stems when the plant is collapsed to the ground, as happens several times during April showers.

Phototropism. Equally likely as a possibility for the enhanced growth, in optical terms, phototropism (Greene (2016); Vandenbrink et al. (2014))is a mechanism by which plants grow towards the sun, in order to optimize the total sunlight absorbed during the day. Sunflowers (Helianthus) are well known to exhibit rotary phototropism (Vandenbrink et al. (2014)), redirecting the flower stems towards the sunlight. Similarly, the wild dandelion (Hypochaeris) is known to open for 8 hours during sunny days (Greene (2016)), and then close during off-peak hours until the next morning.

[1] Study limitations. One possible limitation of this study is the seemingly small sample size of these unusually long flower stems and leaves. While $\mathrm{N}=4,5$ plants is apparently a small sample, the Student's t-test indicates that the results are quite significant, $\mathrm{p}<0.0001$. It is fortunate to observe this unusual type of growth enhancement at all, never before finding this unusual length-doubling effect during many decades of observation.

[2] Seasonal phototropism. Given variable sunlight cues, varying in intensity and direction throughout the day, the daffodil plants evidently elect to face east (Fig. 2a, 2b), west (Fig. 1a), or north (Fig. 1c), as a way to optimize absorbed light, depending on the surroundings. Possibly, facing south is just too bright, as none of the free-standing "open-field" plants observed select this direction, ( $>$ > 30). (For instance, South facing is considered the optimal and brightest direction, on average, for roof-mounted solar cells.) As shown in Figs. 1-2, the plants in each group more-or-less concur on the best direction to optimize lighting effects for each environment.

[3] Another study limitation is a detailed soil analysis. It is possible that because of close proximity to the shrub canopy, diffusion through the soil of an auxin compound could conceivably promote (or discourage) daffodil plant growth (in length only, not stem width or number of flowers, as observed here). In this connection, note that the partially protected plants in Fig. $2 b$ at the edge of the shrub canopy respond only with accelerated flower stem growth, whereas the leaves of the plants developing at the edge remain the same as the control plants. This suggests that the flower stems have a different "motivation" than leaves, responding primarily to phototropic effects, seeking additional sunlight, even at the risk of buckling, whereas the leaves respond primarily to the restraints of rain and wind mechanosensing, tending to delimit rate of growth. 
Future work. The results presented here suggest future laboratory and field research studies with more tightly controlled variables, including temperature, humidity, lighting, hydration, support structures, and soil effects (Heuvelink (1996)).

\section{Practical Applications}

Commercial applications of this unusual rate-doubling effect might include peripheral shrouding of developing plants, during the early growth phase, with a tube or chimney type device. Conceivably, such a device might find application with tomato, corn, cannabis, and potato plants, to name a few.

$n$. $b$. - as of this writing, the exact mechanism for the observed doubling of growth rate remains uncertain, whether "mechanosensing" (likely for the extra-long leaf growth), "phototropism" (likely for enhanced flower stem growth), or some other factor.

"Mechanosensing" per se could be a matter of the shrubbery simply shielding the plant from wind and rain forces, allowing it to grow taller without the risk of breaking, Fig. 1c. Quite likely, the fundamental growth and rate-limiting external effects during development are wind and rain loads, acting as a "stop-signal", causing the unprotected "open-field" daffodils to stop growing at 12 to 16inches ( 0.3 to 0.4 meters) in length, lest they exceed buckling limits. As a similar example, it is well known that tomato plants grow taller when supported by a trellis. With respect to daffodil plants, the shrub canopy provides an "under-pinning" which supports the plant during development.

\section{CONCLUDING REMARKS}

The development of new drugs to control Alzheimer's disease is an important practical application of alkaloid extracts derived from daffodil plants (Hanks (2003)). Thus, factors influencing accelerated growth of daffodil stems and leaves, and therefore the plant cells as well, are of interest. In terms of "phototropism" effects, Waring (1983) discusses extra longitudinal forest tree growth, in response to partial shielding (shading) of the overhead canopy, tending to reduce the intensity of available sunlight. In other words, in a densely populated forest, a longitudinal "growth signal" is conveyed from the photosensitive leaves above to the tree trunk below, encouraging the tree to grow taller, so that more intense sunlight is collected.

Heuvelink (1996) discusses the entire matrix of growth control factors for tomato plants, and other species, in a greenhouse environment, including various types of protective covers, variable lighting, temperature cycling, soil hydration, truss (i.e. flower stem) pruning, atmospheric carbon dioxide, and humidity, developing computer programs which integrate these various effects into a multi-variable predictive model.

In the context of "mechanosensing” as a growth signal, Kutschera (2013)discusses stress-strain and biomechanical processes as applied to the development of sunflower stems. Similarly, Liu et al. (2006) measure and discuss the relative effects of canopy shading and mechanical stress for stoloniferous plants. Perhaps the most important plant applications will come from the weightless environment provided by space station experiments.

\section{REFERENCES}

[1] Greene PR, Greene VA (2017)Stress, Strain-Rate Analysis of Sub-Surface Driveway Plants. Journal of Plant Studies.6(2), 55-65.[PDF] ccsenet.orgStress, Strain-Rate Analysis of Sub-Surface Driveway Plants

[2] Greene PR, Greene VA(2015) Buckling, bending and penetration response of the Taraxacum officinalae (Dandelions) to macadam loading. Australian journal of botany. 63(6), 512-516. [PDF] academia. eduBuckling, bending and penetration response of the Taraxacum officinalae (Dandelions) to macadam loading

[3] Greene PR (2016) Vertical-Lift Potential of the Trapped Hypochaeris radicata (Catsear), a Phototropic Sub-Pavement Plant. Research \& Reviews J of Botanical Sciences. 5(4), 44-46. http://www.rroij.com/ open-access/verticallift-potential-of-the-trapped-hypochaeris-radicata-catseara-phototropic-subpavementplant-.pdf

[4] Hanks GR (Ed)(2003) Narcissus and daffodil: the genus Narcissus. CRC press.https://books.google.com/ books?hl=en\&lr=\&id=4_kH_BffGDgC\&oi=fnd\&pg=PP1\&dq=hanks+narcissus+daffodil\&ots=hfZ6eUNa $\mathrm{zT} \& \operatorname{sig}=\mathrm{YHtt} 0 \mathrm{t} 3 \mathrm{vBDK} 4 \mathrm{kDKRdUxaVfobpqo} \mathrm{v}=$ onepage\&q=hanks\%20narcissus\%20daffodil\&f=false

[5] Kutschera U, Niklas K J(2013) Cell division and turgor-driven stem elongation in juvenile plants: a synthesis. Plant Science. 207, 45-56.[PDF] researchgate.net

International Journal of Advanced Research in Botany (IJARB) 
[6] Vandenbrink JP, Brown EA, Harmer SL, Blackman BK (2014) Turning heads: the biology of solar tracking in sunflower. Plant Science. 224, 20-26.[PDF] escholarship.org

[7] Waring RH (1983) Estimating forest growth and efficiency in relation to canopy leaf area. Advances in ecological research. Academic Press.13, 327-354.[PDF] psu.edu Estimating forest growth and efficiency in relation to canopy leaf area

[8] Liu Y, Schieving F, Stuefer JF, Anten NP (2006) The effects of mechanical stress and spectral shading on the growth and allocation of ten genotypes of a stoloniferous plant. Annals of Botany.99(1), 121130.[HTML] oup.com[HTML] The effects of mechanical stress and spectral shading on the growth and allocation of ten genotypes of a stoloniferous plant

[9] Heuvelink, E. (1996). Tomato growth and yield: quantitative analysis and synthesis. Ph.D. Thesis, Wageningen Agric. Univ., Netherlands, p. 1-326.http://library.wur.nl/WebQuery/wurpubs/fulltext /206832

Citation: Peter R. Greene et al.. "Narcissus (Daffodil) Phototropism, Applications to Alzheimer's Drug Development 'International Journal of Advanced Research in Botany (IJARB), vol. 5, no. 1, pp. 1-7, 2019. http://dx.doi.org/10.20431/2455-4316.0501001

Copyright: () 2019 Authors. This is an open-access article distributed under the terms of the Creative Commons Attribution License, which permits unrestricted use, distribution, and reproduction in any medium, provided the original author and source are credited. 